\title{
Reading notation with Gestalt perception principles ${ }^{1}$
}

\section{Gestalt alg1 ilkeleri ile notasyon okuma}

\author{
Seda Eden Ünlü \\ Ahmet Serkan Ece ${ }^{3}$
}

Abstract

Based on the idea that Gestalt psychology is 'more than all the components that make up it', the emphasis is on the similarities of the brain's functioning during perception, as in reading text. Just as the brain perceives similar letters as holistic rather than one by one, it can be predicted that this happens during the musician's reading score.

Parallel to Gestalt auditory perception research, musicians are thought to benefit from Gestalt perception principles, without consciousness, in the first reading (sight-reading) of notes and later in practice. However, conscious perception of these principles by musicians may be considered to contribute positively during and after their sight-reading.

The aim of this study is to explain various Gestalt perception principles which are supposed to be related to music and to reveal examples of these principles on notation reading. The data obtained from the qualitative research methods through literature review were explained with six basic laws, "Figure-Ground", "Proximity", "Similarity", "Symmetry", "Simplicity" and "Continuity". In the creation of the samples, the principles of visual

\section{Özet}

Gestalt psikolojinin, 'bütün, kendisini oluşturan parçaların bir araya gelmesinden daha fazlasıdır' düşüncesi ile yola çıkarak, tıpkı metin okumada olduğu gibi, nota okumada da beynin algilama esnasındaki işleyişlerinin benzerliklerine vurgu yapilmaktadır. Nasil ki, beyin birbirine benzer harfleri tek tek okumak yerine bütüncül olarak alg1lamaktaysa, söz konusu bu durumun müzisyenlerin nota okuma sirasinda da gerçekleşmekte olduğu öngörülebilir.

Gestalt işitsel alg1 araştırmalarına paralel olarak, müzisyenlerin nota ilk okuma (deşifre) ve daha sonraki pratiklerinde, Gestalt alg1 ilkelerinden, bilincinde olmaksızın, faydalandikları düşünülmektedir. Bununla birlikte müzisyenler tarafindan bu ilkelerin bilinçli olarak algılanması, onların deşifre yapmaları sırasında ve sonraki performanslarında, olumlu yönde katk1 sağlayabileceği düşünülebilir.

$\mathrm{Bu}$ araştırma, müzik ile ilişkili olabileceği varsayılan çeşitli Gestalt alg1 ilkelerini açıklayarak, bu ilkelerin notasyon okuma üzerindeki örneklerini ortaya koyma amacinı taşımaktadır. Nitel araştırma yöntemlerinden literatür taraması yoluyla elde edilen veriler Gestalt alg1 ilkelerinden "Şekil-Zemin",

\footnotetext{
1 This study is the revised and expanded version of the paper presented at the "6th Psychology and Art Symposium" at Bolu Abant Izzet Baysal University, Bolu, Turkey, on November 2-3, 2017.

2 Rsch. Asst, Bolu Abant Izzet Baysal University, Department of Fine Art Education, sedaeden@gmail.com (iD) Orcid ID: 0000-0002-3947-7442

${ }^{3}$ Prof. Dr., Bolu Abant Izzet Baysal University, Department of Fine Art Education, eceserkan@gmail.com (iD) Orcid ID: 0000-0002-1369-5812
} 
perception and the motif, sentence period structures and analyzes, tonic - dominant sentence expressions, tempo and nuance terms that are also included in the auditory perception in music have been related, and it has been attached importance to its concretization with visual perception.

Keywords: Gestalt, musical reading, Gestalt perception principles, sight-reading, transcription.

Extended English summary is at the end of this document)

\section{Giriş}

\subsection{Alg1}

Yapılan araştırmalarda hem felsefenin hem de psikolojinin önemli bir ilgi alanı olan alg1 kavramı, "bir canlının çevresini anlayabilmesi ve anlamaya çalıştı̆̆ bu çevresi ile uyum içinde bulunabilmesi için gerekli bir yaşamsal süreçtir. Alg1, geçmişten günümüze, modern insanın oluşmasında çok önemli bir unsur olarak göze çarpmaktadır”' (Tattersall, 2007, akt. Okay 2011: 48).

Morgan’a göre (1995: 266) “Öğrenirken ve düşünürken kullandığımız duyusal bilgiyi, duyum ve alg1 olmak üzere iki düzeyde işleriz. Duyum bir 1şığın parlaklı̆̆1, bir ses tonunun perdesi, kahvenin sıcaklığı veya iğne battığında duyduğumuz acı gibi ilkel yaşantıları içerir. Duyumlar yaşantının hammaddeleridir; ancak, yaşantı bir dizi duyumdan ibaret değildir. Günlük yaşamımızda duyumlarımızı sürekli olarak bir yorumlama işlemine tabi tutarız. Duyumları yorumlama, onları anlamlı hale getirme sürecine alg1 denir" Yine bir diğer görüşe göre, Plotnik (2009: 124) ise algıyı şu şekilde tanımlamaktadır, "beynimizin binlerce ayrı ve anlamsız duyuyu birleştirip anlamlı bir desen veya görüntüye dönüştürdükten sonra elde ettiğimiz deneyimdir. Duyular anlamsız bilgi parçacıklarıdır. Algılar anlamlı desen, görüntü ve seslerdir”".

Alg1 kavramı göz, kulak, deri, burun, dil gibi beş duyu organıyla alınan uyarıcıların nesnel gerçeklik ve öznel yaşantı boyutları ile etkileşerek organizmayı harekete geçiren anlamlı uyaranlar haline dönüştürülme sürecidir (Aydın, 2005: 161). Bir başka ifadede ise Okay (2011: 49) alg1 ile ilgili görüşünü şu şekilde ifade etmiştir: alg1, duyumdan gelen uyarıcıların işlenerek, farkındalık oluşturma sürecinin tamamıdır.

Duyu organlarımız tarafindan kaydedilen uyarıcıların örgütlenip, yorumlanarak anlamlı hale getirilmesi bir süreç içerisinde ve belirli ilkeler çerçevesinde yapılmaktadır. Bu ilkeler aynı zamanda algısal yaşantılarımızın özellikleri ya da algının özellikleri olarak da adlandırılmaktadır. (Dilekçi, 2012: 43).

\subsection{Gestalt Alg1}

Gestalt terimi, Almanca kökenli olup, kendisini oluşturan parçaların bütününün niteliklerine sahip; alg1 ve algısal örgütlenme alanları içerisinde bir "biçim, durum, figür, sima, şekil, form, bütün" anlamina gelmektedir (Zeren, 2008: 546).

Kuramın gelişimine bakıldığında ise, kuramın ortaya koyulmasının Wertheimer tarafindan olmasına karşın dolaylı olarak kuramın 200 yıllık bir geçmişinin olduğu söylenebilir. "Immanuel Kant (1724-1804), farkındalık deneyiminin duyusal uyaranlar ve zihin etkinliklerinin arasında oluşan bir etkileşimle gerçekleştiğini, başka bir deyişle zihnin uyaranlarda olmayan öğeler katarak bilişsel deneyimi gerçekleştirdiğini söylemiştir. Bir fizikçi olan Ernsnt Mach (1838-1916), belirli nesnelerin 
bağımsız olarak, zaman ve alan olarak düzenlendiği iki algıyı kabul etmiştir. Christian von Ehrenfels (1859-1932) de 1890"eda 'Uber Gestaltqualitaten' (Gestalt Özellikleri Üzerine) adında bir çalışma yazmıstır" (Okay, 2011: 49). "Gestalt teriminin ilk defa bu çalışma içerisinde Ehrenfels tarafindan 1890 yılında kullanıldığına" dikkat çekilmektedir ayrıca Ehrenfels'in yazmış olduğu bu 'Gestalt Özellikleri Üzerine' çalışmasında, görsel anlamdaki 'mekânsal figürler' ve işitsel anlamdaki 'melodi biçimleri’ algısal olarak ilk defa sorgulanmıştır (Smith, 1988: 20). Ehrenfels'e göre bir şeklin üzerinde bulunduğu mekân değiştirildiğinde, o şeklin renk ya da boyut ögelerinde algisal farklıliklar yaşayabiliriz ancak, o şekil kendi şekilsel özelliğinden, örneğin yuvarlak ya da köşeli oluşundan bir şey kaybetmez (Cowan, 1975, 11). Ehrenfels, melodi biçimlerinin de mekânsal figürler gibi Gestalt alg1 içerisinde yer aldığını öne sürmüştür. Gestalt alg1, hem mekânsal hem de zamansal ögelerin üzerinde yer almaktadır (Yazıc1 ve diğ., 2015: 489). Bu noktada Gestalt alg1, kendi ilkeleri doğrultusunda işitsel ve görsel algıyı beraberinde taşımaktadır.

Max Wertheimer (1880-1943)'ın Gestalt kuramını ortaya koymasının ardından, iki öğrencisi Kurt Koffka (1886-1941) ve Wolfgang Köhler (1887-1967), yaptıkları kuramsal ve uygulamaya dönük çalışmalarılla kuramı desteklemişler ve Gestalt Kuramının çerçevesini oluşturmaya katkı sağlamışlardır. Wertheimer algısal organizasyon ilkelerini yaklaşı yüzyıl önce, 1923 yılında 'Gestalt Theory' adı altında bir raporda sunmuştur. Bu raporda Wertheimer, ne zaman farklı şekiller ve biçimler görsek, algımızdaki bir organizasyonun ortaya çıktığını ve bu sayede nesneleri dolaysız ve bütünleşmiş bir şekilde duyumladığımızı savunmaktadır. Bu durum ise, Gestalt Alg1 İlkelerinin temel dayanak noktasını oluşturmaktadır.

$\mathrm{Bu}$ alg1 süreçlerini tanımak ve gestalt alg1 ilkelerini algı süreçleri içerisinde ifade etmek üzere, araştırmada özellikle görsel ve işitsel alg1 deneyimleri anlaşılmaya çalışılmıştır.

\subsubsection{Görsel Gestalt Alg1}

Gestalt psikolojinin temel görüşü, zihnin dış uyaranları parça parça değil de bir bütün olarak görme eğilimidir. Bütünler yapısaldır ve çeşitli örgütleme yasaları ile sınıflandırılır, organize edilirler. Görsel Gestalt alg1 yasaları, dil öğreniminde, görsel sanatlar alanlarında, endüstriyel tasarımda, bilgisayar ve teknoloji üzerine kodlamalarda ve örgütlemelerde siklıkla kullanılmaktadır (Atkinson ve Hilgard, 2015: 155).Görsel Gestalt alg1 çalışmaları, Gestalt algının mekânsal örgütlenmesi içerisinde yer almakta ve Gestalt belirleyicilerinin görsel algı üzerinde etkisi olduğunu açıklamaktadır. Yakınlık ilkesine dayanan araştırmalarda (Banks ve Prinzmetal, 1976; Prinzmetal, 1981; Treisman, 1986) ve benzerlik ilkesine dayanan araştırmalarda (Coren ve Girgus, 1980; Duncan ve Humpphreys, 1989) görsel Gestalt Alg1 ilkelerinin görsel alg1 organizasyonlarında ve görsel alg1 deneyimi süreçlerinde büyük bir rol oynadığı açıkça ifade edilmektedir. "Gestalt Alg1 Yasalar1 görmenin duyu şekliyle (modelitesiyle) ilgilidir. Ancak bu yasalar işitme, dokunma, tatma ve koklama duyu şekilleri için karşılaştırılabilir yasalardır” (Bregman, 1990: 4).

\subsection{2. İşitsel Gestalt Alg1}

Gestalt kuramını açıklama çalışmaları süresince, algısal gruplama çoğunlukla görsel alg1 kapsamında değerlendirilmesine rağmen, gruplamanın aynı belirleyicileri işitmede de ortaya çıkmaktadır. Ernst Mach (1838-1916), bir ezginin tanınmasında, ezginin yazıldığı anahtarın ya da tonun öneminin olmadığının altını çizmiştir. Christian von Ehrenfels (1859-1932) ise dinleyicinin bir ezginin melodik yapısını, notaları tek tek dinleyerek değil birkaç notanın çalınmasıyla fark edebileceğini belirtmiştir. "Ehrenfels'e göre, bir melodi duyarız ve ardından onu tekrar duyduğumuzda, hafızamız bu melodiyi tanımamızı sağlar. Fakat bu melodi farklı bir ton içerisinde transpoze edilerek söylendiğinde, onu yine tanımamızı sağlayan nedir? Elementlerin toplamı (notalar, tonlar) farklıdır ama yine de melodi aynıdır" (Wetheimer, 1924 akt. Yazıcı ve diğ., 2015: 492). "Örneğin, bir melodi, tranpoze yapılarak başka bir tona aktarıldığında bile birey tarafindan melodik olarak aynı algılanır. Çünkü oluşan melodiler tek tek notalardan oluşsa bile, o notaların toplamından farklı olarak algılanır. Ehrenfels 'bütünün algılanışının ve duyumsanmasının' onu 
Eden Ünlü, S., \& Ece, A. S. (2019). Gestalt alg1 ilkeleri ile notasyon okuma. Journal of Human Sciences, 16(4), 1104-1120. doi:10.14687/jhs.v16i4.5822

oluşturan parçalar ile karşılaştırılmasını 'Gestalt nitelikleri' olarak tanımlamışır’' (Smith, 1994 akt. Yazıc1 ve diğ., 2015: 492). İşitsel Gestalt alg1 çalışmaları ise, Gestalt algının zamansal örgütlenmesi içerisinde yer almakta ve Gestalt belirleyicilerinin işitsel alg1 üzerinde de etkisi olduğunu açıklamaktadır. İşitsel Gestalt alg1 ile ilgili ilk önemli çalışmalar (Arnheim, 1954; Huber, 1923; Meyer, 1956; Pratt, 1931; Zuckerandl, 1956), 1920'li yıllara kadar dayanmaktadır.

Gestalt alg1, psikolojinin bir alanı olarak anlaşılmasının yanında, sunmuş olduğu görsel ve işitsel alg1 deneyimleri ile algılama sürecinin psikolojik kökeninin araştırılması ve bu sürecin incelenmesi amacıyla pek çok araştırmacının dikkatini çekmektedir. Gestalt algı yasaları ise, müziğin pek çok farklı unsurdan oluşmasına karşın, bir bütün olarak algılanmasına ve bu sürecin anlaşılmasına yönelik olanaklar sağlamaktadır.

\subsection{Gestalt Alg1 ve Notasyon Okuma}

Gestalt anlayışına göre, beynin birbirine benzeyen parçaları bütünlemesi, müzikal algının bir parçası olan gestalt algının müzisyenlere bir olanak sunduğunu göstermektedir. Yazınsal dildeki harflerin tek tek değil, bir kelime olarak bütünlenerek algılanması, Müzikal dilde de karşımıza çıkmaktadır. Müzikal dil içindeki müzikal metinlerde notalar tek tek değil, aynı kelimeler gibi motifler halinde algilanmaktadır. Levitin (2006: 7) tarafindan da benzer bir görüş şu şekilde ifade edilmektedir: "Notalar bir seri halinde yerleştirildiklerinde, tek bir seri olarak anımsanmak yerine, melodik bir bütün olarak hatırlanırlar". Manno (1993: 99) ise yapmış olduğu araştırmasında, dildeki temel yapıların cümle, cümlecik veya sözcük gruplarının olması gibi, müzikte de temel yapıların ifade, cümle ve alt-cümle gibi terimler olduğunu belirtmiş, müziksel yapıların, dilsel yapılar ile benzer algılandığını vurgulamıştır.

Bütüncül yaklaşımın gestalt psikolojiden geldiğini dile getiren Camp (1992: 10 akt. Okay, 2011: 53) ise, "notadan okuma yapan bir çocuk -nota okumanın ilk bilgilerini elde ettiğinde- müzik sembollerini ölçü gruplaması, ses yükseklikleri, nota değerleri, parmak numaraları ve artikülasyon içinde bir bütün gibi algılamayı öğrenmelidir" ifadesi ile, notasyon okumanın, gestalt alg1 ilkeleri ile örüntülü olduğunu belirtmektedir.

Okay (2011: 54) ise, Gestalt algının, müzik performansçısına verdiği diğer bir olanağın yazılı notadan müzikal metne doğru notaların bütünleştirilerek müzik cümlelerine dönüştürülmesi fikri olduğunu savunmaktadır. Müzikal metinler bütün olarak düşünüldüğünde, notalar tek tek değil, birbirlerinden ayrılmadan algilanmaktadırlar. Bu sayede müzikal cümlelerin algılanması sağlanmaktadır. Özellikle başlangıç düzeyindeki çalg1 öğrencilerinin müzikal yapıları anlamaları ve müzikal cümleleri algılamaları konusunda Gestalt Algı ilkelerinin önemli katkıları ortaya çıkmaktadır.

\subsection{Problem Durumu}

Sistematik ve kuramsal müzik eğitiminde, notalar ve bu notaların yer aldığı notasyonlar temel materyal olarak yer almaktadır. Gestalt alg1 ile yazılı notadan müzikal metne doğru notaların bütünleştirilerek müzik cümlelerine dönüştürülmesi fikrinden hareketle, müzik eğitiminde en sik karşılaşılan sorunlar arasında, müzikal ifade geliştirmek yer almaktadır. Araşturma içerisinde yaşanan bu yaygin duruma çözüm ararken, sorunun notasyon okumaktan da kaynaklı olabileceği üzerinde durulmuştur. Bir diğer ifade ile öğrencinin performans sırasında, müzikal ifade oluşturabilmesinin, notasyonu doğru algılamasına ve gruplayabilmesine de bağlı olduğu görüşünden yola çıkılmıştır. Yapılan araştırmalar incelendiğinde ise, müzik ve gestalt algı araştırmalarının (Bregman, 1990; Bod, 2002; Cambouropoulos, 2006; Camurri ve Leman, 1996; Camurri, Louhivuori, Parncutt ve Schneider, 1997; Cohen ve Dubnov, 1996; Çağlar ve Akbulut, 2017; Deutsch, 1980; Deutsch, 1981; Deutsch ve Feroe, 1981; Handel, 1989; Lerdahl ve Jackendoff, 1983; Leman ve Leman, 1997; McAdams ve Bregman, 1979; Reybrouck, 1997; Tenney ve Polansky, 1980; Terhardt, 1987; Utriainen, 2005) daha çok işitsel alg1 ekseninde yer aldığ1 görülmekte, araştırmalar arasında görsel alg1 ile ilişkilendirilmiş notasyon okuma üzerine bir çalışmaya rastlanmamıştır. Bu araştırmanın, müzik eğitimi alanında öğrencilerin Gestalt algı ilkeleri ile bilinçli olarak notasyon okuyabilmelerine katkısı olacağ1 düşünülmektedir. Bu durumun, öğrencilerin notaları tek tek okumak yerine bir bütün 
Eden Ünlü, S., \& Ece, A. S. (2019). Gestalt alg1 ilkeleri ile notasyon okuma. Journal of Human Sciences, 16(4), 1104-1120. doi:10.14687/jhs.v16i4.5822

halinde cümle gibi okuyabilmeleri, notaları hılı algılayabilmeleri, eserleri müziksel olarak analiz edebilmeleri, kalıcı şekilde hatırlayabilmeleri konularında yapılacak araştırmalara zemin hazırlayacağı düşünülmektedir.

Araştırmada, notasyon okuma sırasındaki bilişsel süreçlerden algılamanın üzerinde özellikle durularak, "Görsel alg1 çerçevesinde, notasyon üzerindeki Gestalt algı ilkeleri nasıl yer almaktadır?" sorusuna cevap aranmıştır.

\subsection{Araştırmanın Amacı}

Betimsel nitelikteki bu tarama araştırmasının amac1, görsel alg1 çerçevesinde Gestalt Alg1 İlkelerinin (şekil/zemin, yakınlık, benzerlik, simetri, basitlik ve süreklilik) her biri ile notasyon okuma arasındaki ilişkiyi ortaya koymaktır. Ayrıca bir diğer amacı ise, literatürde yer alan gestalt ve müzik araştırmaları arasında, 'işitsel algılama ve müzik' araştırmalarının yanı sıra, 'görsel algılama ve müzik’ araştırmalarına da dikkat çekilmek istenmesidir. Bu amaç doğrultusunda, Gestalt Alg1 İlkelerinin, notasyon okuma ile ilişkilendirilebilineceği vurgulanmış, yapılan bu araştırmanın daha sonraki araştırmalara 1ş1k tutacağı düşünülmüsstür.

\section{Yöntem}

Araştırma, betimsel nitelikte tarama araştırmasıdır. Veri toplama aracı olarak, notasyon örneği için, 'Viyola Öğretimine Yönelik Örnek Etüt Analizi’ başlıklı çalışmada (Özdemir ve Dalkıran, 2013: 142) da etüt analizi gerçekleştirilmiş olan viyola eğitiminde kullanılan, Adolf Grünwald Sibemol Major etüt ve yaylı çalgı quartet için Johann Pachelbel - Canon eseri ele alınmıştır. Veri toplama yöntemi olarak, ilgili literatür taraması yapılmış, Gestalt algı ilkeleri notasyon üzerinde görsel şekiller ve grafikler ile belirtilerek gösterilmiş, notasyon okuma üzerinde ilişkilendirme çalışmalanı yapılarak veriler karşılaştırılmıştır. Araştırmanın kapsam geçerliliği için ise, uzman görüşleri (Psikoloji, Psikolojik Danışmanlık ve Rehberlik Öğretmenliği ile Eğitim Bilimleri alanlarından beş öğretim üyesi) alınmıştır. Araştırma, notasyon okuma sırasında görsel Gestalt alg1 ile ve Gestalt alg1 ilkelerinden, şekil-zemin, yakınlık, benzerlik, simetri, basitlik, süreklilik yasaları olmak üzere altı algılama yasası ile sınırlandırılmıştır.

\section{Bulgular}

\subsection{Gestalt Alg1 İlkeleri ve Notasyon Okuma Arasındaki İlişkiler}

Gestalt psikologları, algılama ve alg1lama esnasındaki örgütlemenin gerçekleşebilmesi için, beynimizin bir dizi kurala uyduğunu ve bu kurallar sayesinde ayrı ayrı parçaların anlamlı bir şekil ya da örüntü oluşturmak için organize edildiği görüşünü savunmaktadır. (Plotnik, 2009: 126) Duyu organlarından aldığımız verilerin bir araya gelip oluşturduğu bütünlüğe ise 'algıda örgütleme' denilmektedir (Koyuncu, 2016: 179). Gestalt yaklaşımına göre alg1, bir örgütlemedir.

Gestalt kuramına göre, belirsiz durum ya da olaylar, insanın bütünde alg1lama eğilimi olduğu için, bireyi rahatsız eder. İnsan bu durumun üstesinden gelmek için bir takım bütünlemeler ve örgütlemeler yapar. Bu bütünleme ve örgütlemeleri yaparken de, beynin daha öncesinde koymuş olduğu kurallar çerçevesinde, algıda örgütleme ilkelerinden yardım alır. "Bu örgütleme ilkeleri arasında 100'ün üzerinde alg1 yasası yer almaktadır” (Dilekçi, 2012: 46). Çeşitli araştırmalarda, Gestalt Örgütlenme Yasalar1, Gestal Alg1 Kuralları, Gestalt Alg1 Örgütleme İlkeleri olarak da yer almaktadırlar. $\mathrm{Bu}$ araştırma içerisinde, bu yasalar arasından, en çok bilinenlerden, şekil-zemin, yakınlık, benzerlik, simetri, basitlik, süreklilik yasaları olmak üzere altı algılama yasası ele alınmakta, bu yasaların notasyon okuma ile ilgili ilişkileri açıklanmaktadır. 
Eden Ünlü, S., \& Ece, A. S. (2019). Gestalt alg1 ilkeleri ile notasyon okuma. Journal of Human Sciences, 16(4), 1104-1120. doi:10.14687/ihs.v16i4.5822

\subsection{1. Şekil / Zemin (Figure / Ground) Yasas1}

Tüm algılamalarda bir şekil ve zemin vardır. Şekil, zeminden daha büyüktür ve belirgindir ancak arka yüzeyi oluşturan zemin içinde anlam kazanır. Şekil 1'deki şekil ve zemin yer değiştirebilir. Bu durumda alg1 organizasyonunuza göre, birbirine dönük iki yüz görebileceğiniz gibi bir vazo da görebilirsiniz (Schultz ve Schultz, 2007: 541).

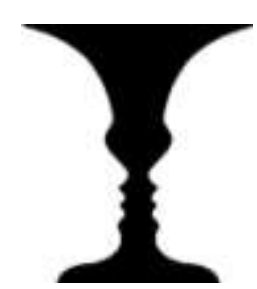

Şekil 1 Alg1sal Organizasyon Şekil-Zemin Yasası Örneği

Gestalt Alg1 yasalarından şekil zemin yasası, notasyon okumanın temeli niteliğinde görülebilir. Notalar şekli, dizek çizgileri ise zemini temsil etmektedir. Her bir nota görünümünün hangi sese ait olduğu, hangi dizek çizgisinde yer aldığına göre farklılık göstermektedir. Şekil 2 'de bulunan notaların hangi sese ait olduğu ve Şekil 3’te bulunan dizek olduğu sürece belirlenebilir. Bir başka ifade ile notalar bulundukları çizgilere göre anlam kazanmakta, şeklin hangi ses olduğu ve hangi frekansı temsil ettiği bulunduğu zemin üzerinde belirli olmaktadır.

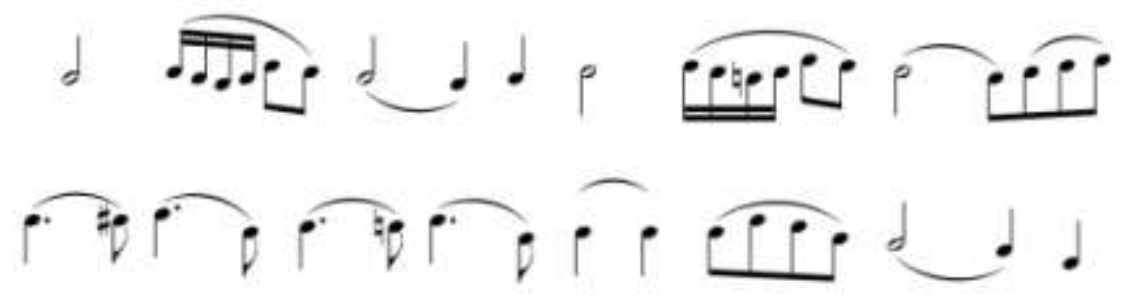

Şekil 2: Şekil-Zemin Yasası Şekil için Notasyon Örneği

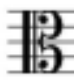

Şekil 3: Şekil-Zemin Yasası Zemin için Notasyon Örneği

\subsubsection{Yakınlık (Proximity) Yasası}

Zaman veya mekânda birbirine yakın olan parçaları ayrı ayrı algılamak yerine birlikte algılama eğilimi vardır. Örneğin Şekil 4’ün ikinci kısmında yer alan daireler geniş bir grup içinde algılanmaktan ziyade, üç sütun şeklinde algıllanırlar (Schultz ve Schultz, 2007: 540). Bu yasa en çok, konuşma, okuma ve yazma süreçleri içerisinde kullanılmaktadır. İnsanlar konuşurken duraksamamalarına rağmen, dilin özelliklerine göre kelimeleri, ses yapılarını algılar ve organize ederek anlamlandirirlar.

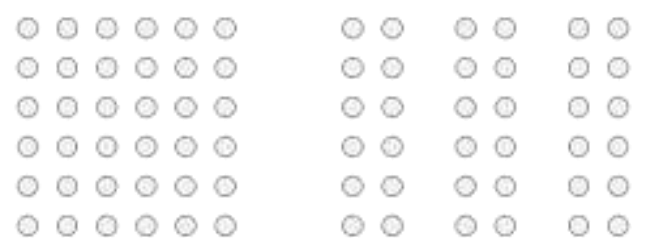

Şekil 4: Algısal Organizasyon Yakınlık Yasası Örneği 
Eden Ünlü, S., \& Ece, A. S. (2019). Gestalt alg1 ilkeleri ile notasyon okuma. Journal of Human Sciences, 16(4), 1104-1120. doi:10.14687/jhs.v16i4.5822

Yakınlık yasası, notasyon okumada ve yazmada sıklıkla kullanılmaktadır. Notaların süre değerlerinin ifade edilmesinde, kısa süreli notalar yazıllırken kendisinden sonra gelen notaya metrik olarak yakın, uzun süreli ise kendisinden sonra gelen notaya uzak yazıllılar. Notaların sürelerinin kısalığı yakın, uzunluğu uzak yazma ile gruplanmaktadır. Bu durum içerisinde, şekil 5’te olduğu gibi, Gestalt Alg1 Yasaları çerçevesince, uzun süreli notalar, daha sade bir görünüm, kısa süreli notalar ise daha karmaşık bir görünüm sunmaktadır. Insan zihni notaları okurken ve yazarken, notaları yakınlıklarına göre gruplandırıp, ritmik gruplamayı görsel olarak alg1landığı öngörülmektedir.

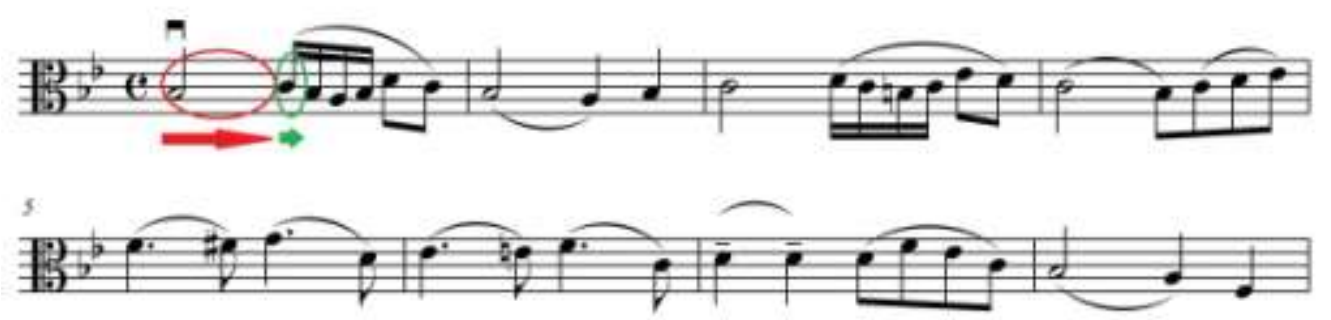

Şekil 5: Yakınlık Yasası için Notasyon Örneği

\subsubsection{Benzerlik (Similarity) Yasası}

Benzer biçim ve şekle sahip daireler ve noktalar kendi aralarında gruplanarak görüldüğ̈unden, sütunlar halinde değil, sattrlar halinde dikkat çekmektedirler (Koyuncu, 2016: 185). Şekil 6'da da ifade edildiği üzere, birbirine benzer parçalar bir grup oluşturacak şekilde birlikte algilanirlar.

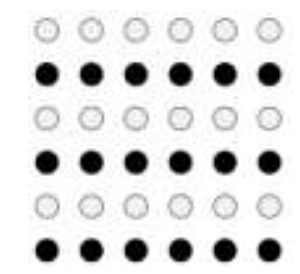

Şekil 6: Algisal Organizasyon Benzerlik Yasası Örneği

Notasyon üzerindeki notalar okunurken ve yazilırken birbirlerine benzerlikleri ile anlaşılmakta ve benzer basamaklar (sekvensler) oluşturmaktadırlar. Şekil 7'de gösterilmekte olduğu gibi, birinci ve üçüncü dizeğin, birinci ve üçüncü ölçüleri kendi içlerinde; ikinci dizeğin birinci ve ikinci ölçüleri kendi içlerinde; dördüncü dizeğin birinci ve ikinci ölçüleri ise yine kendi içlerinde görsel örüntü olarak birbirleri ile benzerlik göstermektedir.

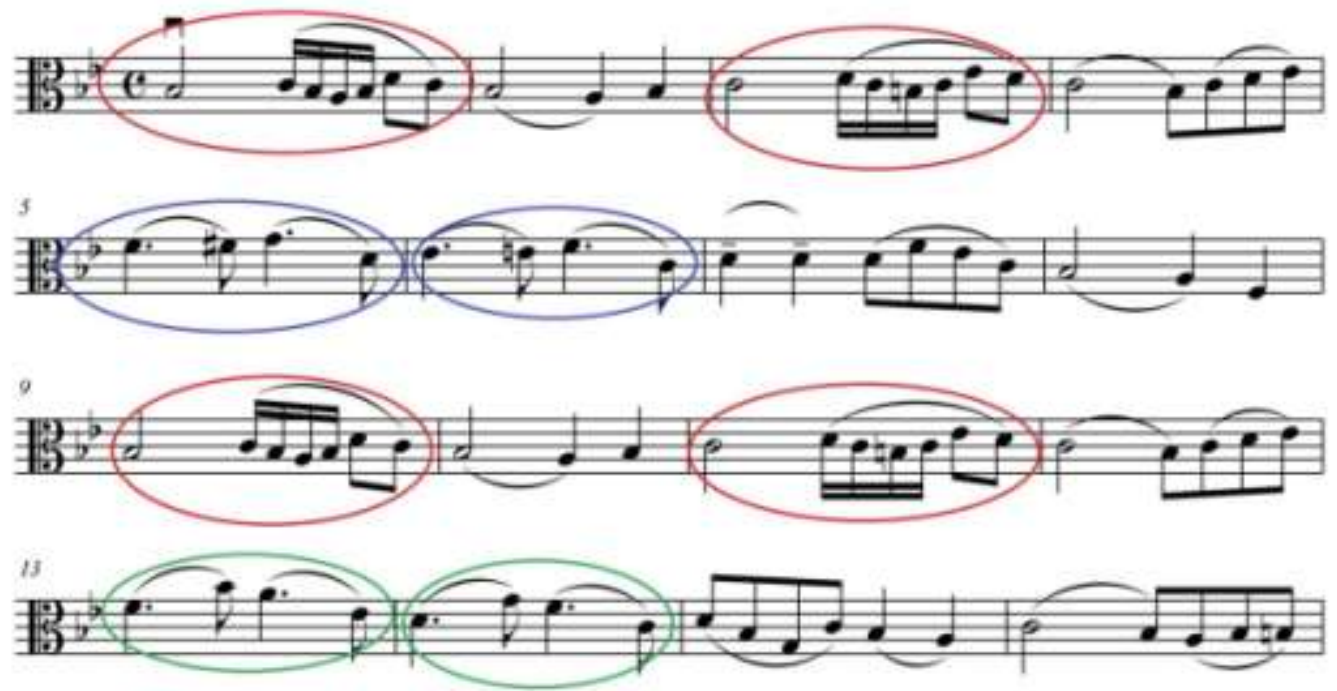

Şekil 7: Benzerlik Yasası için Notasyon Örneği 
Eden Ünlü, S., \& Ece, A. S. (2019). Gestalt alg1 ilkeleri ile notasyon okuma. Journal of Human Sciences, 16(4), 1104-1120. doi:10.14687/ihs.v16i4.5822

\subsubsection{Simetri (Symmetry) Yasas1}

Akıl bir nesneyi, simetrik olarak ve bir merkez etrafinda şekillendirerek algilamaktadır. Nesneleri eşit sayıda simetrik olarak bölmek algısal olarak memnuniyet vericidir. Birbirine bağlı olmayan iki simetrik parça verildiğinde akıl uyumlu bir şekilde algisal olarak organize etmektedir. İnsan algisı, Şekil 8'de yer almakta olan altı parantezi, 3 simetrik çift parantez olarak algilamaktadır. Simetri, görsel sanatlar alanlarında yaygın olarak kullanılmakta ve çoğu zaman birbirinin tekrarı olan parçaların bir arada kullanılmasıyla oluşturulmaktadır. Birimlerin matematiksel tekrarına dayalı simetrik bir düzenlemeyle bütünlük sağlanmaktadır (Yağmur, 2014: 154).

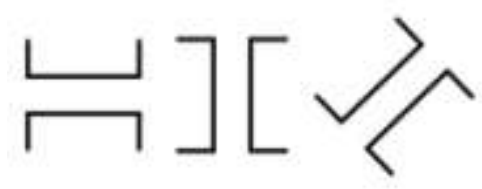

Şekil 8: Algısal Organizasyon Simetri Yasası Örneği

Notasyon okuma sırasında özellikle motif, cümle, dönem gruplamaları yapılırken, simetri yasasından faydalanılmaktadır. Kelime dilindeki, söz öbekleri, cümlecikler ve cümleler olduğu gibi müzikte de, motifler, cümlecikler, cümleler yer almaktadır. Özellikle dikte yazma sırasında dizekteki toplam ölçü sayılarının eşit bölünmesi, dikte yazma sırasında notaların motiflenerek yazılmasının yanı sıra, cümlelenerek yazılmasını da sağlayacaktır. Şekil 9'da gösterildiği gibi, benzer motiflerin, dağınık bir şekilde (dizek ortasında ya da dizek başında olmasına bakılmaksızın) yazılmasının yerine, Şekil 8'de olduğu gibi alt alta yazılmasının, gestalt alg1 örgütlemesi içerisinde simetri yasasından faydalanılarak, notasyon okumada kolaylık sağlayabileceği öngörülmektedir.
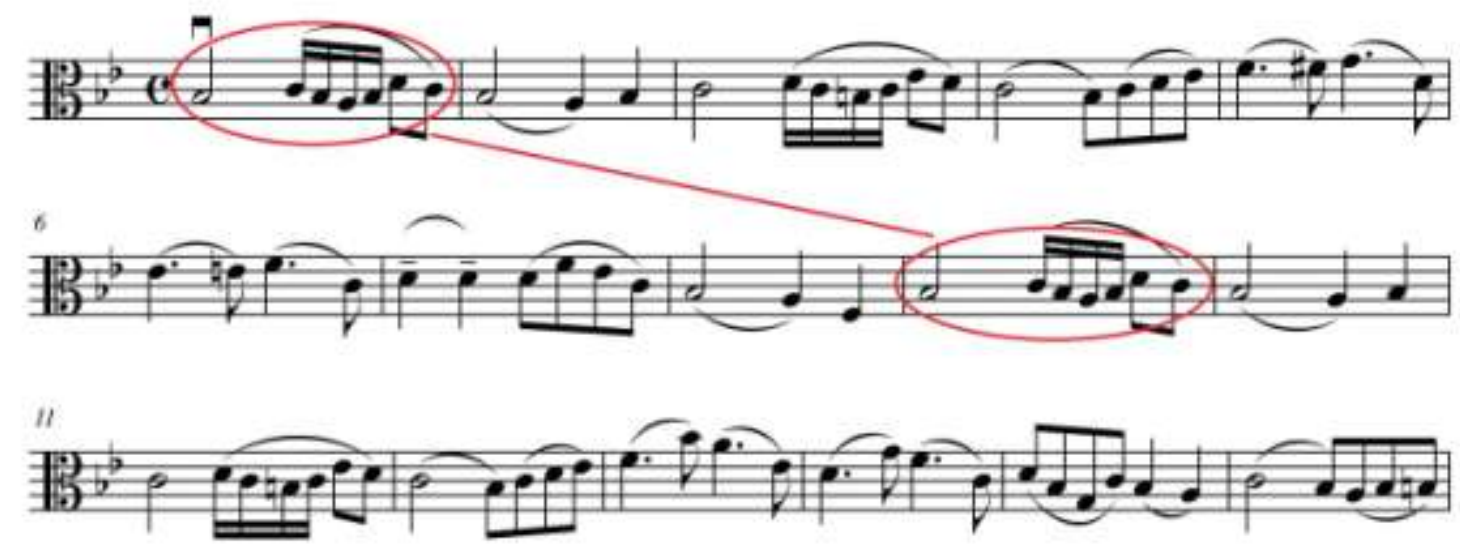

Şekil 9: Simetri Yasası için Notasyon Örneği

\subsubsection{Basitlik (Pragnanz - Simplicity) Yasas1}

Gestalt psikologları bir figürün mümkün olduğu kadar 'iyi görülme’ eğiliminde algılandığını ve buna pragnanz veya 'iyi şekil' denilmekte olduğunu ifade etmektedirler (Goldstein, 2013: 123). İyi bir gestalt. basit ve sabit olup, daha basit hale getirilemeyendir. (Schultz ve Schultz, 2007: 541). Rock ve Palmer (1990: 88), iyi dizilmiş şekillerin birbiri ile hızlı eşleşmekte olduklarının, daha kolay hatırlandıklarının, kısa ve öz şekilde tanımlandıklarının altını çizmektedir. Şekil 10'da bulunan çizgiler iyi Gestalt 'a örnek olarak verilebilir çünkü zihin basitlik yasası sayesinde, X'i oluşturan çizgileri, > ve < birleşimi olarak görmek yerine, \ve / birleşimi olarak algilamaktadır.

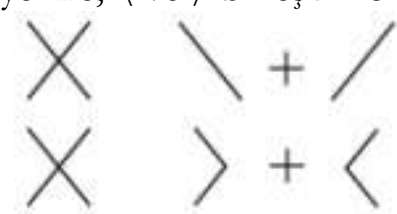

Şekil 10: Algısal Organizasyon Basitlik Yasası Örneği 
Eden Ünlü, S., \& Ece, A. S. (2019). Gestalt alg1 ilkeleri ile notasyon okuma. Journal of Human Sciences, 16(4), 1104-1120. doi:10.14687/jhs.v16i4.5822

Notasyon okuma sırasında, notaların süre değerlerine göre yazılması okuyucu için önem taşımaktadır. Şekil 11'deki birinci dizeğin birinci ölçüsü ile, üçüncü dizeğin birinci ölçüsü, notasyon olarak birbirinin aynısını temsil etmektedir. Ancak insan alg1s1, her zaman basiti okumaya öncelikli olduğu için üçüncü dizekteki belirtilen nota yazımını daha çabuk ve rahat kavrayabilmektedir. Birinci dizeğin birinci ölçüsündeki nota karmaşasından uzaklaşmak ve daha sade yazım sağlayabilmek adına, müzikte süre değerlerine göre nota yazımı kullanılmakta, bu durum ise karşımıza Gestalt Alg1 ilkelerinden basitlik yasasının notasyonun hemen hemen her evresinde karşımıza çıktığını göstermektedir.

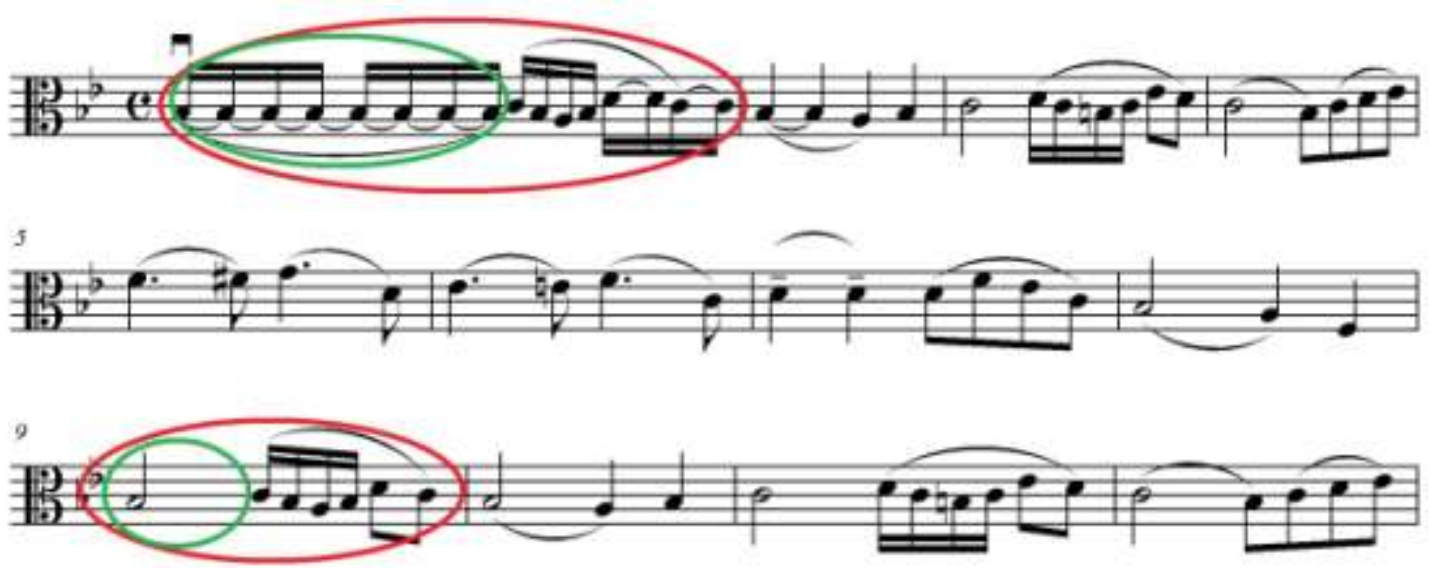

Şekil 11: Basitlik Yasası için Notasyon Örneği

\subsubsection{Süreklilik (Continuity) Yasası}

Bir alandaki ögeler aynı yönde giden bir örüntü oluşturmaktadır. Algı alanında bulunan ve aynı yönde giden ögeler, çizgiler, birimler birbirleriyle ilişkili görünme eğilimindedirler (Koyuncu, 2016: 183). Bu eğilim, süreklilik olarak ifade edilmektedir. Şekil12 incelendiğinde, küçük dairelerin oluşturduğu şekil yukarıdan aşağıya doğru algılanma eğilimi içerisindedir.

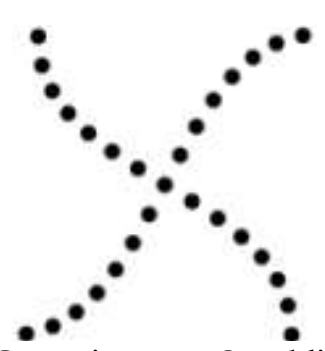

Şekil 12: Algısal Organizasyon Süreklilik Yasası Örneği

Notasyon üzerinde süreklilik yasası, sürekli tekrar eden motif (ostinato), olarak karşımıza çıkmaktadır. Bir deşifre sırasında eserin bir partisi baştan sona aynı motifi, ezgiyi ya da cümleyi devam ettirebilmektedir. Baştan sonra bir akış halinde olduğu ve bir sonu yokmuşçasına süreklilliğini sağlayabildiği için, riffler, sürekli baslar ya da ostinatolar notasyon örneklerinde sürekliliği ifade eden örnekler olarak karşımıza çıkmaktadırlar. Şekil13 incelendiğinde Pachelbel'e ait olan Canon eserinde, üçüncü partinin, eser süresince sekiz notadan oluşan dört ölçülük bir motifi devam ettirdiği görülmektedir. Çeşitli notasyonlar incelendiğinde, süreklilik yasasının pek çok örneği ile karşılabilmektedir. 
Eden Ünlü, S., \& Ece, A. S. (2019). Gestalt alg1 ilkeleri ile notasyon okuma. Journal of Human Sciences, 16(4), 1104-1120. doi:10.14687/jhs.v16i4.5822

\section{Canon}
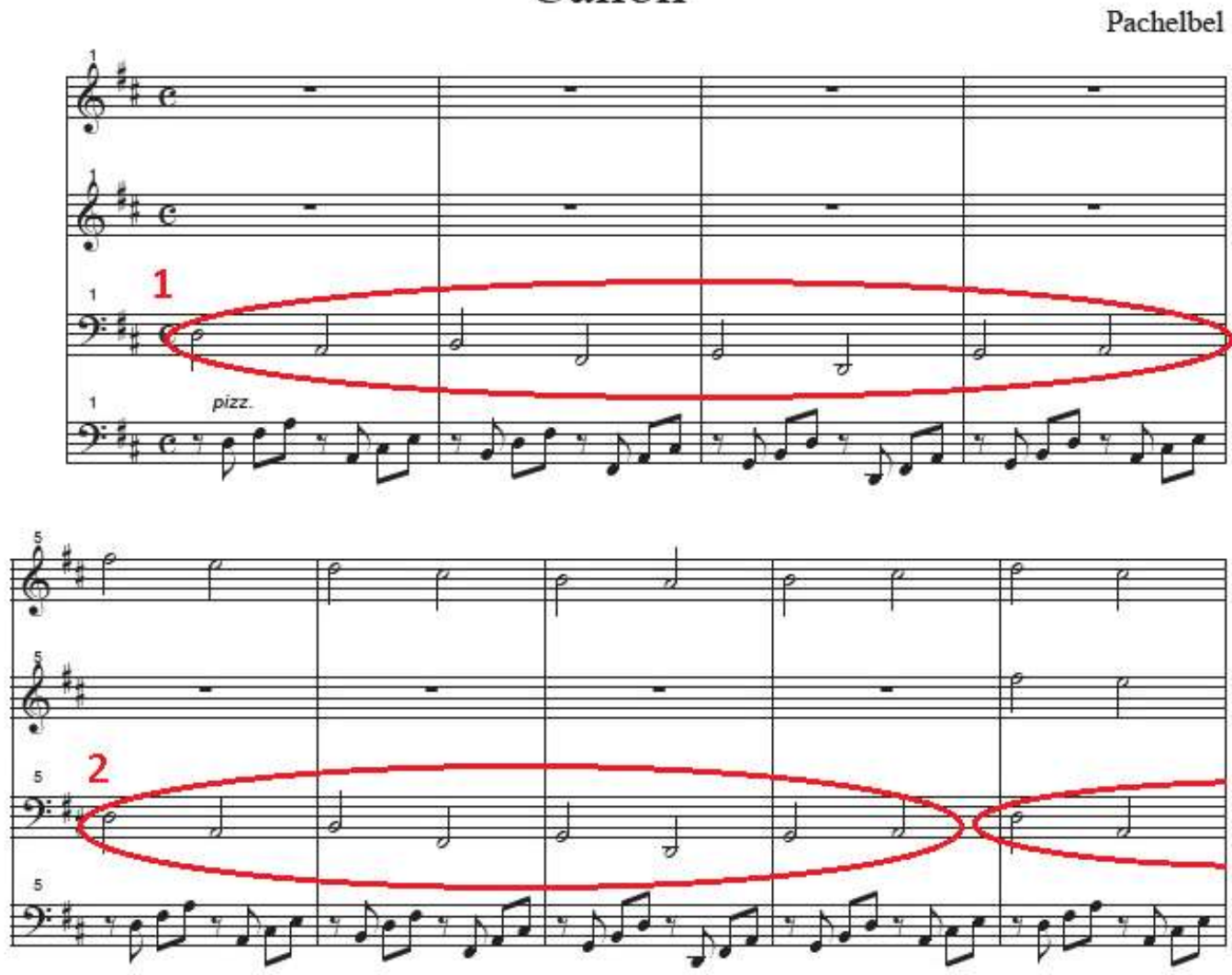

Şekil 13: Süreklilik Yasası için Notasyon Örneği,

\section{Sonuç, Tartışma ve Öneriler}

Gestalt alg1 ilkeleri, Gestalt psikolojinin en önemli kavramlarından biri olan ve bütünün algısal yönden en basit ve en iyi bütün olma eğilimine dayandığını ifade eden yasalar altında toplanmıştır. Diğer bir ifade ile en iyi şekil, en iyi bütün olma eğilimindedir. Notasyon okuma sırasında da, okunan notanın alg1 açısından en basite indirgenerek, en iyi şekil ile okunduğu düşünülmektedir. Nota okuyan kişi, notasyon üzerindeki tüm unsurları, gestalt alg1 ilkeleri ile gruplandırıp onları bir bütün olarak düşünmeli ve ona göre seslendirme yapmalıdır. Gestalt Kuramının bilişsel kuramın başlangıcı olduğu göz önünde bulundurulunca, notasyon okuma üzerinde de iyi organize edilmiş notaların okunmasının algı açısından daha etkili ve verimli öğrenme sağladığ1 düşünülmektedir. Araştırmada görsel alg1 çerçevesinde, Gestalt Alg1 İlkelerinin Notasyon Okuma üzerindeki yansıması şu şekilde yer almaktadır.

1. Şekil / Zemin (Figure / Ground) İlkesi ile notasyon okumakta olan birey, dizeği zemin, notaları ve müzikal sembolleri şekil olarak algılar. Şekil, zemine göre daha belirgin olduğu için, dizeğe odaklanmaksızın notalar okunur. Ancak notaların hangi frekansta olup, hangi sesi temsil ettiğini bulunduğu dizek belirler. Bir diğer ifade ile, notalar bulundukları dizek üzerinde anlam kazanırlar. Sloboda (1985) ve Dowling (1989: 250), gerçekleştirdikleri işitsel algiya dayalı araştırmalarında, müziğin çoklu katmanlardan oluştuğundan ve müzikal dokunun karmaşıklığından bahsetmektedirler. Ayrıca Gestalt alg1 içinde bu karmaşık doku içindeki katmanlardan birine, şekil; bunların bulunduğu toplama ise, zemin adını vermiştir. Çağlar ve Akbulut (2017: 29) ise "zemin algisında eşlik durumundaki parti veya partiler, eserin altyapısını oluşturarak şeklin müzikal akışını destekleyen duyuşsal bir fon gibi hareket edebilmektedir" ifadeleri ile Gestalt ve şekil-zemin ilişkisini yine işitsel algı açısından değerlendirmişlerdir. Sonuç olarak şekil-zemin ilkesinin, müziğin tınısal ve yazınsal tüm aşamalarında, notasyon okuma sırasındaki görsel ve işitsel alg1 süreçlerinde yer aldığ1 söylenebilmektedir. 
2. Yakınlı (Proximity) İlkesi ile notasyon okumakta olan birey, uzun süreli notayı kendisinden sonra gelen notaya olan uzaklığ1, kısa süreli notayı ise kendisinden sonra gelen notaya olan yakınlığı ile algılar. Ayrıca onaltılık, otuzikilik gibi kısa vuruşlu notaların dörderli olarak gruplanıp kümelenmesi, nota saplarının birbirine bağlanması ve birbirine yakın yazılması da yakınlık ilkesi ile ilişkili olarak yer almaktadır. Bod (2002: 27) müzikal gruplamada, Gestalt'ın yakınlık, benzerlik ve paralellik ilkelerinden yararlanıldığını belirtmiştir. Zentz, (1992: 34) ise notasyondaki yakınlık ilkesini, aynı vuruş içerisindeki akor gruplamasının dikey olarak tek bir çizgi üzerinde yer almasında görüldügünü, izole tek bir nota yerine, akor grubu olarak algılandığını ifade etmektedir. Coren ve Girgus (1980: 406) ise, yapılan bu araştırmaya paralel olarak, insanların algısal gruplandırmalar içerisinde bulunan parçaların arasındaki mesafeleri, diğer gruplandırma içerisinde bulunan parçalara göre daha küçük mesafeler olarak değerlendirdiklerini ifade etmiştir. Tenney ve Polansky (1980: 236) ve Reybrouck (1997: 7), müzikal yapının eşzamanlı olmasına ve buna bağlı olarak ardışık kod çözme becerisine ihtiyaç duyulmasına dikkat çekmişler, eşzamanlı kod çözmenin operasyonel yaklaşımı içerisinde yakınlık ilkesinin önemine vurgu yapmışlardır. Wurtz, Mueri ve Wiesendanger (2009: 449), karmaşık bir piyano eserinin notalarını okurken, notaların tekil notalar olarak değil akor veya "gestalt" olarak algılandığını, bunun için muazzam bir deneyim, hafıza ve yetenek gerektiğini ifade etmektedir. Sloboda (1976: 13), tarafindan gerçekleştirilen araştırmada ise, rastgele yerleştirilmiş notaların algilanmasındaki gruplandırma faktörlerinin, rastgele oluşturulan harflerin algilanmasında olduğundan daha önemli olabileceğinin üzerinde durulmuştur. Her notanın dizek üzerinde mutlak bir konumunun olmasına rağmen; ayrıca diğer notalarla ilgili konumunun notasyon algısını düzenlemek için kullanılabilecek olmasına vurgu yapılmıştır. Notasyondaki gruplandırmalar oluşturulurken, tekil nota okumak yerine bütünlük esas alınarak işitsel algıdaki notaların işlevlerine de dikkat çekilmek istenmiştir.

3. Benzerlik (Similarity) İlkesi ile notasyon okumakta olan birey, birbirlerine benzeyen ve benzer basamaklar (sekvensler) oluşturan nota kümelerini (motifleri) birlikte algılarlar. Bu benzerliği nota okuma sırasında görebilmeleri, onlara cümle düşünebilme ve form analizi konularında olumlu yönde etki sağlamaktadır. Bu konuda Lerdahl ve Jackendoff (1983: 251), melodik gruplamanın; Cambouropoulos (2006: 250) ise melodik segmentasyonun önemine vurgu yaparak, müziksel öğelerin belirli bir zaman dilimi içinde, benzerliklerine göre bitişik segmanlar halinde gruplandığını ifade etmişlerdir. Wolf (1976: 145) ise nota okuma üzerine yapmış olduğu araştırmasında, nota okuma sırasında desen- motif tanımanın ve benzer müzikal dokuları görmenin önemini ortaya koymaktadır.

4. Simetri (Symmetry) İlkesi ile notasyon okumakta olan birey, dizekteki toplam ölçü sayılarının eşit bölünmesi, notaların motiflenerek yazılması ile notaları cümleleyerek okuyabilecektir. Benzer motiflerin, dağınık bir şekilde (dizek ortasında ya da dizek başında olmasına bakılmaksızın) yazılmasının yerine, alt alta yazılması, gestalt alg1 örgütlemesi içerisinde simetri yasasından faydalanıldığını göstermektedir. Bu faydanın ise notasyon okumada kolaylık sağlayabileceği öngörülmektedir.

5. Basitlik (Pragnanz - Simplicity) İlkesi ile notasyon okumakta olan birey, notaların süre değerlerine göre yazılması sayesinde notaları karmaşıklıktan uzak ve rahat okuyacaktır. Notaların süre değerlerine göre yazılması okuyucu için önem taşımaktadır. İnsan alg1sı, her zaman basiti okumaya öncelikli olduğu için bağlarla birbirine bağlanan notaları okumak yerine kısaca uzun sesi temsil eden notaları daha çabuk ve rahat kavrayabilmektedir. Nota karmaşasından uzaklaşmak ve daha sade yazım sağlayabilmek adına, müzikte süre değerlerine göre nota yazımı kullanılmakta, bu durum ise karşımıza Gestalt Alg1 ilkelerinden basitlik yasasının notasyonun hemen hemen her evresinde karşımıza çıktığını göstermektedir.

6. Süreklilik (Continuity) İlkesi ile notasyon okumakta olan birey, sürekli tekrar eden ve ostinato görevi gören motifleri, eser boyunca bir döngü içerisinde seyir eden ve sürekliliği olan cümleler olarak algılar. Bir eserde, eserin bir partisi baştan sona aynı motifi, ezgiyi ya da cümleyi devam ettirebilmektedir. Baştan sonra bir akış halinde olduğu ve bir sonu yokmuşçasına sürekliliğini 
sağlayabildiği için, riffler, sürekli baslar ya da ostinatolar notasyon örneklerinde sürekliliği ifade eden örnekler olarak karşımıza çıkmaktadırlar. Batchelor (2015: 19) araştırmasında, melodilerin genellikle bas çizgilerinde, gestalt ilkelerinden sürekliliğin görülmekte olduğunu ifade etmiştir.

Tüm bu ilkelerin 1şığında, Gestalt Alg1 ilkelerinin notasyon okuma sırasında görsel alg1 ve işitsel alg1 perspektifinde yadsınamaz bir yer edindiği, notasyon okumanın neredeyse her bir sürecinin Gestalt alg1 ilkeleri ile ilintili olduğu sonucuna ulaşılmaktadır. Bu konuda Bean (1938: 1), yaklaşık yüz yıl önce gerçekleştirmiş olduğu araştırmasında, müzik okuma yetersizliğinin çeşitli hatalara dayandığının altını çizmekte, bu alanda müzik okuma sürecinin anlaşılmasından önce çözülmesi gereken çok sayılda sorun olduğunu belirtmekte ve bu sorunlardan birinin çoğu müzik öğretmeninin nota okumadaki Gestalt becerisini öğrenmede ihmal edilmiş olduğunu vurgulamaktadır. Bu durumun günümüzde de sürekliliğini koruduğu düşünülmektedir. Bu konu gerçekleştirilecek olan bir durum tespit çalışmasının 1şık tutabileceği düşünülmektedir.

Camp (1992: 12), müzik eğitimindeki notasyon okumanın önemini "müzik eğitimine yeni başlayan bir öğrencinin notayı nasıl algılayacağını öğrenmesi, müzikal öğrenmenin temeli olarak öğrencinin müzik kavramlarını şekillendirmesinde çok büyük etki yaratacaktır" şeklinde ifade etmektedir. Çoban ve Okay (2013: 259) ise, "Gestalt algiy1 bilmek, gerek müzikal performansta bilişsel süreçlerin işleyişini tanımak gerekse müzikal performansta her bir bileşenin önemini anlamak konusunda önemlidir" cümlesi ile kulak eğitiminde ve çalg1 eğitiminde nota okurken Gestalt algının önemini vurgulamaktadır. Müzik eğitiminde notasyon okumanın önemi ve notasyon üzerindeki Gestalt alg1 ilkelerinin önemi ortadayken, Schellenberg (2001: 368)'in araştırmasinda ise, müzik derslerinin gestalt alg1 ilkelerine dikkat etmek ve farkındalık sağlamak gibi birçok genel beceriyi geliştirme olasıllğının yüksek olduğu ifade edilmektedir. Sonraki araştırmalarda, kulak eğitimi ve çalg1 eğitimi başlangıç seviyelerinde, nota okuma sırasındaki gestalt algı ilkelerinin kullanımına ve ve bu alg1 ilkeleri kullanımının deşifre başarı durumuna yansımasına yönelik deneysel desenlerin konuya 1şık tutacağ1 düşünülmektedir. Notasyon okumanın, Gestalt alg1 ilkelerine dayandığ1 m1 yoksa Gestalt algı ilkelerinin farkındalı̆̆ını geliştirdiği mi paradoksunun yanıtı gelecekte yapılacak olan araşturmalar ile temele yaslanabilecektir.

\section{Kaynaklar}

Atkinson \& Hilgard (2015). Psikolojiye Giriş (14. Baskı). Çeviren: Öznur Öncül, Deniz Ferhatoğlu. Arkadaş Yayınevi, Ankara.

Arnheim, R. (1954). Art and visual perception. Berkeley. University of Califormia Press, Ltd, 197(4), 96-161.

Aydın A. (2005). Gelişim ve Öğrenme Psikolojisi. Ankara: Tekağaç Eylül Kitap Yayın Dağıtım.

Banks, W. P. \& Prinzmetal, W. (1976). Configurational effects in visual information processing. Perception \& Psychophysics, 19(4), 361-367.

Batchelor, D. W. (2015). Gestalt Principles in Ligeti's Piano Etude 'Desordre". Doctoral dissertation University of South Carolina. Retrieved fromhttps://scholarcommons.sc.edu/etd/3634

Bean, K. L. (1938). An experimental approach to the reading of music. Psychological Monographs, 50(6), 1 80.http://dx.doi.org/10.1037/h0093540

Bod, R. (2002). Memory-based models of melodic analysis: Challenging the Gestalt principles. Journal of Nen Music Research, 31(1), 27-36.

Bregman, A. S. (1990). Auditory Scene Analysis: The Perceptual Organization of Sound. Cambridge, MA: MIT Press. https://doi.org/10.1016/B0-08-043076-7/00663-X

Cambouropoulos, E. (2006). Musical parallelism and melodic segmentation:: A computational approach. Music Perception, 23(3), 249-268.

Camp, M.W. (1992). Teaching Piano: The Synthesis of Mind, Ear and Body. USA: Alfred Publishing Co., Inc.

http:/ /books.google.com.tr/books?id $=$ ohCY9r609DsC\&printsec $=$ frontcover $\#_{\mathrm{v}}=$ onepage\&q\&f=f alse

Camurri, A. \& Leman, M. (1996, September). Gestalt-based composition and performance in multimodal environments. In Joint International Conference on Cognitive and Systematic Musicology (pp. 495-508). Springer, Berlin, Heidelberg. 
Eden Ünlü, S., \& Ece, A. S. (2019). Gestalt alg1 ilkeleri ile notasyon okuma. Journal of Human Sciences, 16(4), 1104-1120. doi:10.14687/jhs.v16i4.5822

Camurri, A., Louhivuori, J., Parncutt, R. ve Schneider, A. (1997). Music, gestalt, and computing: Studies in cognitive and systematic musicology (Vol. 1317). Springer Science \& Business Media.

Cohen, D. \& Dubnov, S. (1996, September). Gestalt phenomena in musical texture. In Joint International Conference on Cognitive and Systematic Musicology (pp. 386-405). Springer, Berlin, Heidelberg.

Coren, S. \& Girgus, J. S. (1980). Principles of perceptual organization and spatial distortion: the gestalt illusions. Journal of Experimental Psychology: Human Perception and Performance, 6(3), 404.

Cowan, E. (1975). Gestalt Psychology: An Introduction. Chaplain (MAJ), ABD.

Çağlar E. ve Akbulut F. (2017). Müzikal Alg1 ve Deşifrede Gestalt Yaklaşımı. International Journal of Social Science 61(3), 25-36.

Çoban, S. ve Okay, H. H. (2013) Yaylı Çalg1 Eğitiminde Müzikal İfadenin Geliştirilmesi1. İdil Dergisi(2)7, $255-$ 279. DOI: 10.7816/idil-02-07-15.

Deutsch, D. (1980). The processing of structured and unstructured tonal sequences. Perception \&o Psychophysics, 28(1), 381-389.

Deutsch, D. (1982). Grouping mechanisms in music. D. Deutsch (Editör), The Psychology of Music (2. bask1, s. 99-134). San Diego: Academic Press.

Deutsch, D. \& Feroe, J. (1981). The internal representation of pitch sequences in tonal music. Psychological Review, 88(6), 503-522

Dilekçi N. (2012)İngilizce Sözcük Öğretiminde Tipografinin Etkisi. Yayımlanmamış Yüksek Lisans Tezi. Abant İzzet Baysal Üniversitesi, Eğitim Bilimleri Enstitüsü, Bolu.

Dowling, W. J. (1989). Simplicity and complexity in music and cognition. Contemporary music review, 4(1), 247253.

Duncan, J. \& Humphreys, G. W. (1989). Visual search and stimulus similarity. Psychological review, $96(3), 433$.

Goldstein E. B. (2013). Bilişsel Psikoloji. Kaknüs Yayınlan, İstanbul.

Grünwald, A. Die ersten Violin-Übungen. Elementarunterricht. No:29, 26-27. Edition Peters, no: 1985,

Handel, S. (1989). Listening: An Introduction to the Perception of Auditory Events. Cambridge, MA: The MIT Press.

Huber, K. (1923). Der ausdruck musikalischer elementarmotive, eine experimentalpsychologische untersuchung. JA Barth.

Koyuncu, B. (2016).Gestalt Kuramı. G. Ekici (Ed.), Öğrenme-Öğretme Kuramları ve Uygulamadaki Yansimaları (167-193). Ankara: Pegem Akademi.

Manno, M.A. (1993). An investigation into the nature of musical expression and its application in elementary piano teaching. Unpublished Doctoral Theses, The University of Texas, USA.

Morgan, C. (1995). Psikolojiye Giriş (11.Bask1), Çeviren: Sirel Karakaş, Hacettepe Üniversitesi Psikoloji Bölümü Yayınları, Yayın no: 1.

Lerdahl, F. \& Jackendoff, R. (1983). An overview of hierarchical structure in music. Music Perception: An Interdisciplinary Journal, 1(2), 229-252.

Leonard, M. (1956). Emotion and meaning in music. The University of Chicago Press, London.

Leman, M., \& Leman, M. (1997). Music, gestalt, and computing. Springer Berlin Heidelberg.

Levitin, D. J. (2006). This is your brain on music: The science of a human obsession. Penguin.

McAdams, S. \& Bregman, A. (1979). Hearing musical streams. Computer Music Journal, 3(4), $26-43$.

Morris, C. G. (2002) Psikolojiyi Anlamak, Çeviren: H. Belgin Ayvaşı, Melike Sayıl. Ankara: Türk Psikologlar Derneği Yayınları No:23.

Okay, H. H. (2011). Eğitim Fakültesi Müzik Eğitimi Anabilim Dalı Yaylı Çalgı Eğitiminde Şarkımsı Çalışa Bağlı Olarak Müzikal İfadenin Geliştirilmesi. Marmara Üniversitesi, Eğitim Bilimleri Enstitüsü, İstanbul.

Özdemir, G. ve Dalkıran, E. (2013). Viyola Öğretimine Yönelik Örnek Etüt Analizi. İnönü Üniversitesi Sanat ve Tasarm Dergisi, 1(2).

Pachelbel, J. Canon and Gigue in D major, P.37.

Plotnik, R. (2009). Psikolojiye giriş. Çeviren: Tamer Geniş. İstanbul:Kaknüs Yayınları. ISBN 978-975-256095-6. 1.Bask1.

Pratt, C. C. (1931). 1968. The meaning of music: A study in psychological aesthetics, New York: Johnson.

Prinzmetal, W. (1981). Principles of feature integration in visual perception. Perception \& Psychophysics, 30(4), $330-340$.

Reybrouck, M. (1997). Gestalt concepts and music: Limitations and possibilities. In Music, Gestalt, and Computing (pp. 57-69). Springer Berlin Heidelberg.

Rock, I., \& Palmer, S. (1990). The legacy of Gestalt psychology. Scientific American, 263(6), 84-91. 
Eden Ünlü, S., \& Ece, A. S. (2019). Gestalt alg1 ilkeleri ile notasyon okuma. Journal of Human Sciences, 16(4), 1104-1120. doi:10.14687/jhs.v16i4.5822

Schellenberg, E. G. (2001). Music and nonmusical abilities. Annals of the New York. Academy of Sciences, 930(1), 355-371.

Schultz D. P. \& Schultz S. E. (2007). Modern Psikoloji Tarihi. Çeviri: Yasemin Aslay. Kaknüs Yayınları, İstanbul.

Sloboda, J. A. (1976). Visual perception of musical notation: Registering pitch symbols in memory. Quarterly Journal of Experimental Psychology, 28(1), 1-16.

Sloboda, J. A. (1985). The musical mind: The cognitive psychology of music. Oxford University Press.

Smith, B. (1988). Gestalt theory: An essay in philosophy. B. Smith (Editör), Foundations of Gestalt Theory (s. 1181). Munich ve Vienna: Philosophia

Tenney, J., \& Polansky, L. (1980). Temporal gestalt perception in music. Journal of Music Theory, 24(2), $205-241$.

Terhardt, E. (1987). Gestalt Principles and Music Perception. In Auditory Processing of Complex Sounds, ed. William A. Yost and Charles Luatson, pp. 157-166. Hillsdale, N.J.: Lawrence Erlbaum Associates

Treisman, A. (1986). Features and objects in visual processing. Scientific American, 255(5), 114-125.

Utriainen, J. (2005). A Gestalt music analysis: philosophical theory, method, and analysis of Iegor Reznikoff's compositions. University of Jyväskylä, Finland.

Wolf, T. (1976). A cognitive model of musical sight-reading. Journal of psycholinguistic research, 5(2), 143-171.

Wurtz, P., Mueri, R. M., \& Wiesendanger, M. (2009). Sight-reading of violinists: Eye movements anticipate the musical flow. Experimental brain research, 194(3), 445-450.

Yağmur, Ö. (2014). Minimal Sanatta Dan Flavin'i Gestalt Alg1 Kuramıyla Anlamlandırma. Güzel Sanatlar Enstitüsü Dergisi, (33), 150-162.

Yazıcı Z. F., Doğrusöz Dişiaçık N. ve Mungan E. (2015) Müzikte Algısal Gruplama I, Akademik Bakıs Dergisi, 51(5) (pp. 488-507).

Zentz, D. M. (1992). Music learning: Greater than the sum of its parts. Music Educators Journal, 78(8), 33-36.

Zeren. S.. G. (2008). Gestalt Kuramı, İ. Yıldırım (Ed.), Gelişim Psikolojisi. Ankara:Anı Yayıncılık.

Zuckerkandl, V. (1969). Sound and Symbol, Vol. 1: Music and the External World. Translated by Willard R. Trask. Princeton, NJ: Princeton University Presss

\section{Ekler}

\section{Ek-1}

\section{Extended English Summary}

\section{Introduction}

According to the Gestalt approach, the brain's integration of similar parts shows that Gestalt perception, which is a part of musical perception, offers musicians an opportunity. The perception of the letters in the literary language by integrating them as a word, not one by one, also appears in the musical language. In musical texts in musical language, notes are perceived not as individual but as motifs like the same words. A similar view is expressed by Levitin (2006: 7): "When notes are placed in a series, they are remembered as a melodic whole instead of being remembered as a single series". Manno (1993: 99) in his research, the basic structures in the language, such as sentences, clauses or word groups, the basic structures in music, such as expression, sentence and sub-sentence stated that the terms, such as musical structures, linguistic structures are perceived similar to emphasized.

Camp (1992: 10 cf. Okay, 2011: 53) states that, holistic approach comes from Gestalt psychology, with the expression, "a child who reads from the score, -when you get the first knowledge of nota reading- should learn to perceive music symbols as a whole in measure grouping, volume levels, note values, finger numbers and articulation" score reading is in line with gestalt perception principles.

In systematic and theoretical music education, the notes and the notations with these notes take place as the basic material. Developing musical expression is one of the most common problems in music education with the idea of integrating the notes from the written note to musical text into musical sentences with Gestalt perception. While looking for a solution to this common 
situation in the research, it was emphasized that the problem might also be caused by notation reading. In other words, it is concluded that the student's ability to form a musical expression during performance depends on the correct perception and grouping of notation. When the researches (Bregman, 1990; Bod, 2002; Cambouropoulos, 2006; Camurri ve Leman, 1996; Camurri, Louhivuori, Parncutt ve Schneider, 1997; Cohen ve Dubnov, 1996; Çağlar ve Akbulut, 2017; Deutsch, 1980; Deutsch, 1981; Deutsch ve Feroe, 1981; Handel, 1989; Lerdahl ve Jackendoff, 1983; Leman ve Leman, 1997; McAdams ve Bregman, 1979; Reybrouck, 1997; Tenney ve Polansky, 1980; Terhardt, 1987; Utriainen, 2005) are examined, it is seen that music and gestalt perception studies are mostly located on the axis of auditory perception, and no studies on notation reading related to visual perception have been found.

\section{Purpose}

The aim of this descriptive survey is to reveal the relationship between each of the Gestalt Perception Principles (figure / ground, proximity, similarity, symmetry, simplicity and continuity) and notation reading within the framework of visual perception. It is also aimed to draw attention to 'visual perception and music' research as well as 'auditory perception and music' researches among the gestalt and music researches in the literature. For this purpose, it was emphasized that Gestalt Perception Principles could be associated with notation reading, and this study was thought to shed light on later studies.

\section{Method}

The research is descriptive survey research. As a data collection tool, for the notation example, 'Viyola Öğretimine Yönelik Örnek Etüt Analizi' (Özdemir and Dalkıran, 2013: 142), it was used in viola education Adolf Grünwald - Bb Major etude and Johann Pachelbel-Canon for string instrument quartet. As a data collection method, related literature was searched, Gestalt perception principles were indicated by noting visual figures and graphs on notation, and correlation studies were made on notation reading and the data were compared. For the content validity of the study, expert opinions (five faculty members from the fields of Psychology, Psychological Counseling and Guidance Teaching and Educational Sciences) were obtained. The research is limited to visual Gestalt perception during notation reading and to six perception laws which are the principles of Gestalt perception, figure-ground, proximity, similarity, symmetry, simplicity, continuity laws.

\section{Results and Implications}

The principles of Gestalt perception are gathered under laws which are one of the most important concepts of Gestalt psychology and that the whole is based on the tendency to be the simplest and best whole perceptually. In other words, the best shape tends to be the best of all. During notation reading, it is thought that the read note is reduced to the simplest in terms of perception and read in the best way. The person reading the note should group all the elements on the notation with the principles of gestalt perception and think of them as a whole and make a voice accordingly. Considering that Gestalt Theory is the beginning of cognitive theory, it is thought that reading well organized notes on notation reading provides more effective and efficient learning in terms of perception. In the study, the reflection of Gestalt Perception Principles on notation reading within the framework of visual perception is as follows.

1. Figure / Ground Principle: Figure / Ground Principle with the principle of reading the individual notation, staff ground, notes and musical symbols as a figure. Since the figure is more pronounced than the ground, sheet music is read without focusing on the staff. However, the staff determines the frequency at which the notes are represented and which sound they represent. In other words, the notes gain meaning on the staff they are on. Sloboda (1985) and Dowling (1989: 250), in their research based on auditory perception, mention that music is composed of multiple layers and the complexity of musical tissue. 
You can also figure one of the layers within this complex texture, within Gestalt perception; and the collection in which they are called the ground. Çağlar and Akbulut (2017: 29) stated that score, accompanying the perception of the ground can act as an affective fund that supports the musical flow of the form by forming the infrastructure of the work and evaluated the Gestalt and figure-ground relationship in terms of auditory perception. As a result, it can be said that the figure-ground principle is involved in the visual and auditory perception processes during notation reading at all stages of musical and literary music.

2. Proximity Principle: The person who reads notation with the Proximity Principle perceives the long-term note with the distance to the next note and the short-term note with the proximity to the next note. In addition, the grouping and clustering of short-beat notes such as semi-quaver and triple croche, the binding of note stems to each other and writing close to each other are also related to the principle of proximity. Bod (2002: 27) stated that Gestalt's proximity, similarity and parallelism principles were used in musical grouping. Zentz, (1992: 34), the principle of proximity in the notation, chord grouping in the same beat is seen to be located on a single line vertically, it is perceived as a chord group instead of an isolated single note. Coren and Girgus (1980: 406) stated that in parallel with this research, people consider the distances between the parts in perceptual groupings as smaller distances than the parts in the other grouping. Tenney and Polansky (1980: 236) and Reybrouck (1997: 7) emphasized the importance of the principle of proximity in the operational approach of concurrent decoding. Wurtz, Mueri and Wiesendanger (2009: 449) state that when reading the notes of a complex piano work, the notes are perceived as chords or gestalts, not singular notes, and require tremendous experience, memory and ability. In the study conducted by Sloboda (1976: 13), it was emphasized that the grouping factors in the perception of randomly placed notes may be more important than the perception of randomly generated letters. Although each note has an absolute position on the staff; it was also emphasized that the position of the other notes could be used to regulate the perception of notation. In forming the groupings in notation, attention was paid to the functions of notes in auditory perception on the basis of integrity rather than reading notes.

3. Similarity Principle: The person who reads notation with the similarity principle, perceives the sets of motifs that are similar to each other and form similar steps. The fact that they can see this similarity during note reading gives them a positive effect on sentence thinking and form analysis. In this regard Lerdahl and Jackendoff (1983: 251), melodic grouping; Cambouropoulos (2006: 250) emphasized the importance of melodic segmentation and stated that musical elements are grouped into adjacent segments according to their similarities within a certain period of time. Wolf (1976: 145), in his research on note reading, reveals the importance of recognizing patterns and motifs and seeing similar musical textures during note reading.

4. Symmetry Principle: The person who reads notation with the symmetry principle, will be able to read the notes in sentences by dividing the total number of measurements in the string, writing the notes with motifs. Instead of writing similar motifs scattered (regardless of whether they are in the middle of the staff or in the begin of the staff), they are written one under the other, indicating that the law of symmetry is utilized within the organization of gestalt perception. It is foreseen that this benefit will provide ease in notation reading.

5. Simplicity Principle: The person who reads notation with the simplicity principle, will be able to read the notes easily and without any complexity. It is important for the reader to write notes according to the time values. Because human perception is always a priority for simple reading, instead of reading the notes connected by ties, it is possible to comprehend the notes representing the long voice more quickly and easily. In order to get away from the clutter of notes and to provide more simple writing, note writing is used according to time 
Eden Ünlü, S., \& Ece, A. S. (2019). Gestalt alg1 ilkeleri ile notasyon okuma. Journal of Human Sciences, 16(4), 1104-1120. doi:10.14687/jhs.v16i4.5822

values in music, and this shows that the law of simplicity, which is one of the Gestalt Perception principles, appears in almost every stage of notation.

6. Continuity Principle: The person who reads notation with the continuity principle, perceives the repetitive and ostinato motifs as sentences that run through a cycle and have continuity. In a work, a score of the work can maintain the same motif, melody or sentence from start to finish. Since it is in a flowing state from the beginning and can provide continuity as if it has no end, riffs appear as continuous bass or ostinatolar notation samples expressing continuity. Batchelor (2015: 19) stated that the continuity of gestalt principles is seen on the bass lines of melodies.

In the light of all these principles, it is concluded that Gestalt Perception principles have gained an undeniable place in the perspective of visual perception and auditory perception during notation reading, and that almost every process of notation reading is related to Gestalt perception principles.

Ek-2
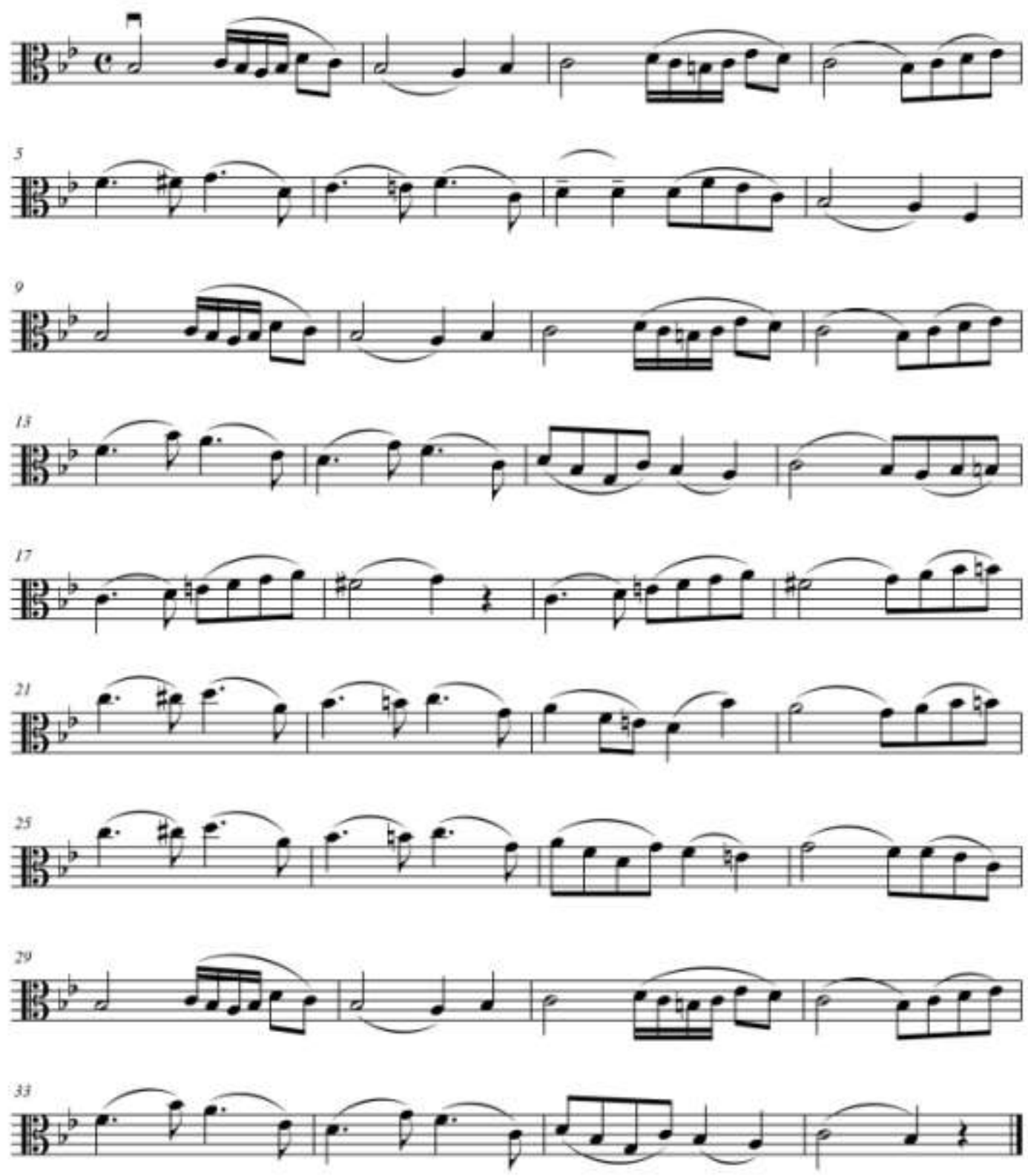

Ek 2: Grünwald, A. Die ersten Violin-Übungen Etüt no. 29 